\title{
Preparation and Evaluation of Controlled Release Tablets Containing Mefenamic Acid
}

\author{
Mohammad Usman ${ }^{3}$, Irshad Ali ${ }^{1}$, Hafsa Bibi ${ }^{1}$, Javeid Iqbal ${ }^{2}$ and Kashif Iqbal ${ }^{3 *}$ \\ ${ }^{1}$ Department of Chemistry, Gomal University, Dera Ismail Khan, KPK, Pakistan \\ ${ }^{2}$ Faculty of Pharmacy, Hamdard University, Karachi, Pakistan \\ ${ }^{3}$ Mohi-Ud-Din Islamic Institute of Pharmaceutical Sciences, MIU, Mirpur, AJK
}

\begin{abstract}
In the present study, Mefenamic acid $200 \mathrm{mg}$ controlled release matrices were prepared by direct compression and in vitro drug dissolution studies were performed to find out the drug release rate and patterns. Methocel was used as rate controlling polymer. Also the effect of several co-excipients was investigated on the drug release rates during in vitro dissolution studies. Polymer Methocel was used as a rate controlling polymer and was formulated with the drug at 4 different $\mathrm{D}$ : $\mathrm{P}$ ratios. Phosphate buffer $\mathrm{pH} 7.2$ was used as dissolution medium using PharmaTest dissolution apparatus. Several kinetic models were applied to the dissolution profiles to determine the drug release kinetics. Dissolution equivalency evaluation was performed using $f_{2}$ similarity factor.
\end{abstract}

Keywords: Mefenamic acid; Controlled release tablets; Methocel; Co-excipients

\section{Introduction}

In the last several decades, several types of dosage forms have been developed by scientists with certain patient favourable modifications, one of which is the oral drug delivery system which is the oldest one and has got popularity in for more than a century. Oral drug delivery system have the advantages that these are easy to administer, ease of manufacturing and higher patient compliance. In oral drug delivery systems certain modifications were done to achieve certain specific objectives, the most profound need of which was to maintain constant drug plasma concentrations for a certain period of time to reduce the dosage frequency which was achieved by controlled release drug delivery systems [7].

Despite of the advancements in other drug delivery systems, oral sustain/controlled release drug delivery systems is dominating the market and have an increased safety and patient compliance [5]. These dosage forms can deliver the drug in a predetermined manner to the site of action (Hamza et al., 2010). To control the release of drug from a controlled release dosage forms, polymers are used, which release the drug in a slow and nearly constant manner to obtain nearly constant peak plasma level [1,7]. The drug is release from such type of controlled release matrices occurs by diffusion or degradation $[1,7]$.

Mefenemic acid is a non steroidal anti inflammatory drug commonly known as NSAID's and is used to treat pain and to reduce inflammation. Its exact mechanism of action is not known but is suggested to inhibit prostaglandin synthesis. Mefenamic acid is also suggested in premenstrual migraine headache prophylaxis. It is chemically 2-(2, 3-dimethylphenyl) amino benzoic acid [6].

\section{Material and Methods}

$\mathrm{NaOH}$ (Merck, Germany), Mono basic potassium phosphate, CMC, Starch, Mefenamic Acid (Bio Labs Pharma Islamabad, Pakistan), Lactose and Magnesium stearate ( BDH Chemical Ltd., Pool England), Methocel E4M Premium EP (Dow Chemical Co., Midland USA), PharmaTest Dissolution Apparatus, Single Punch Tablet machine (Erweka AR 400, Germany), UV-Visible spectrophotometer (UVIDEC-1601 Shimadzu, Japan), Friability Tester (Erweka TA3R, Germany) and Hardness Tester (Erweka Apparatus TB24, Germany).

\section{Formulation of tablets}

Mefenamic acid $200 \mathrm{mg}$ controlled release matrix tablets were prepared using $100 \mathrm{mg}$ drug and weighing concentrations of polymer and excipients as shown in table 1 . Starch was used as filler and magnesium stearate was used a lubricant.

\section{Evaluation of mix powder}

Mefenamic acid-Methocel tablets mixed powder was evaluated using several methods. The angle of repose was determined using funnel method. For the determination of compressibility index cylindrical method was used. All these tests were performed according to USP specifications.

\section{Preparation of tablets}

Drug and polymer was taken in mortar and was grind to fine powder than all other excipients were added except lubricant. This mixture was passed through 20 sieve size mesh for three times and then lubricant was added and again passed through the same sieve. The prepared powder was compressed to tablets using single punch tableting machine at an average hardness of $7 \mathrm{~kg} / \mathrm{cm}^{2}$.

\begin{tabular}{|l|l|l|l|l|}
\hline Drug & D: P ratio & Polymer & Filler (Lactose) & Lubricant (0.5\%) \\
\hline Mefenamic acid-Methocel CR tablets \\
\hline $100 \mathrm{mg}$ & $10: 01$ & $10 \mathrm{mg}$ & $89 \mathrm{mg}$ & $1 \mathrm{mg}$ \\
\hline $100 \mathrm{mg}$ & $10: 02$ & $20 \mathrm{mg}$ & $79 \mathrm{mg}$ & $1 \mathrm{mg}$ \\
\hline $100 \mathrm{mg}$ & $10: 03$ & $30 \mathrm{mg}$ & $69 \mathrm{mg}$ & $1 \mathrm{mg}$ \\
\hline $100 \mathrm{mg}$ & $10: 04$ & $40 \mathrm{mg}$ & $59 \mathrm{mg}$ & $1 \mathrm{mg}$ \\
\hline \multicolumn{5}{|c}{ Table 1: Formulation Of Mefenamic acid $200 \mathrm{mg}$ tablets. } \\
\hline
\end{tabular}

*Corresponding author: Kashif Iqbal, Mohi-Ud-Din Islamic Institute of Pharmaceutical Sciences, MIU, Mirpur, AJK, Tel: 0092-333-9959480; E-mail: kashifiqbal321@gmail.com

Received March 16, 2012; Accepted April 19, 2012; Published April 20, 2012

Citation: Usman M, Ali I, Bibi H, Iqbal J, Iqbal K (2012) Preparation and Evaluation of Controlled Release Tablets Containing Mefenamic Acid. Clin Exp Pharmacol 2:107. doi:10.4172/2161-1459.1000107

Copyright: ( 2012 Usman M, et al. This is an open-access article distributed under the terms of the Creative Commons Attribution License, which permits unrestricted use, distribution, and reproduction in any medium, provided the original author and source are credited. 


\section{Evaluation of tablets}

Hardness of the tablets was determined by hardness tester (Erweka Apparatus TB24, Germany) and dimensional tests were performed using Vernier calliper. The friability of the tablets was determined using Friability tester (Erweka TA3R, Germany).

\section{In vitro dissolution study and drug release kinetics}

PharmaTest dissolution apparatus was used for the in vitro drug release studies of Mefenamic acid controlled release tablets by using rotation method according to USP; the rotation was kept constant at $100 \mathrm{rpm}$. Phosphate buffer $\mathrm{pH} 7.2$ was used as a dissolution solvent, each station of the apparatus containing $900 \mathrm{ml}$. Samples each $5 \mathrm{ml}$ were withdrawn from the stations at specific time intervals for the analysis of drug concentration. The drug concentration in each sample was analyzed using UV visible spectrophotometer at $350 \mathrm{~nm}$ wavelength.

The data of dissolution profiles were fitted in several kinetic models and drug release mechanism from tablets were calculated. These kinetic models include Zero order kinetics, First order kinetics, Hixson Crowell's Equation, Higuchi's Square Root of Time Equation and Korsmeyer Pappas equation.

\section{Dissolution equivalancy}

To find out the similarities and dissimilarities between the drugs release profiles of developed formulations and reference standard conventional tablets, the similarity factor $\mathrm{f}_{2}$ was applied according to FDA $[2,3]$, according to the following formula:

$$
\mathrm{f}_{2}=50 \log \left\{\left[1+1 / \mathrm{nW}_{\mathrm{t}} \sum_{\mathrm{t}=1}^{\mathrm{n}}\left(\mathrm{R}_{\mathrm{t}}-\mathrm{T}_{\mathrm{t}}\right)^{2}\right]^{-0.5} \times 100\right\}
$$

\section{Results}

In the presented study, controlled release tablets of Mefenamic acid were prepared for optimized drug release patterns during in vitro dissolution studies. Various formulations were prepared containing varying amount of polymer in order to see the effect of polymer concentration on drug release rates.

The prepared mixed powder was physically evaluated with some parameters and was suggested to be suitable for compression into tablets. The average compressibility index of the mixed powder of all the formulations was $14 \pm 3 \%$ and average angle of repose was $39^{\circ}$ \pm 2 which indicates that the mixed powder was having good flow properties.

Mefenamic acid controlled release tablets were evaluated for some physical tests. Average hardness of CR tablets was $7.6 \pm 2 \mathrm{~kg} /$ $\mathrm{cm}^{2}$, average friability was $0.22 \pm 3 \%$, average thickness was $2.3 \pm 3$ $\mathrm{mm}$ and average diameter was $8 \pm 2 \mathrm{~mm}$ which were all in acceptable USP ranges.

The release of Mefenamic acid from controlled release tablets prepared at 4 different $\mathrm{D}$ : $\mathrm{P}$ ratios and the affects of different coexcipients on drug release rates can be seen from the figures 1 and 2 below. It was observed that about $100 \%$ drug was released in $8 \mathrm{hrs}$ from the preparations prepared at D: $\mathrm{P}$ ratio $10: 1$, while the most extended drug release profiles were observed from the formulation prepared at $D$ : $P$ ratio 10:4. Several co-excipients were added to investigate their effect on drug release rates which showed that they successfully enhanced the drug release rates from matrix tablets in the order $\mathrm{CMC}>\mathrm{HPMC}>\mathrm{MC}$.

The values of kinetic models employed reveals that the drug was released from polymeric tablets exhibiting non-Fickian transport mechanism. Similarity factor $f_{2}$ was employed to find out the similarities between the release profiles of drug from the test with the reference standard formulation and it was observed that there was no similarities between the release profiles of the formulations from the test as compared to reference standard as the values of $\mathrm{f}_{2}$ were smaller than 50 (range 50-100).

\section{Discussion}

As shown from the figure 1 above Mefenamic acid was released from the formulations prepared at four different D: $\mathrm{P}$ ratios in the manner that the shortest release time were exhibited by the formulation prepared at D: P ratio 10:1 i.e. 9 hrs and the longest drug release time were exhibited by the formulation prepared at D: P ratio 10:4 i.e. $24 \mathrm{hrs}$ which can conclude that by increasing the concentration of polymer the drug release rate could be prolonged [7]. Methocel polymer was found to successfully extend the drug release profiles from matrix tablets. The addition of co-excipients such as CMC, HPMC and MC

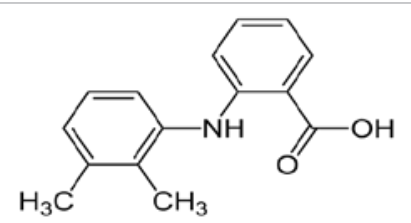

Figure 1: Structure of Mefenamic Acid

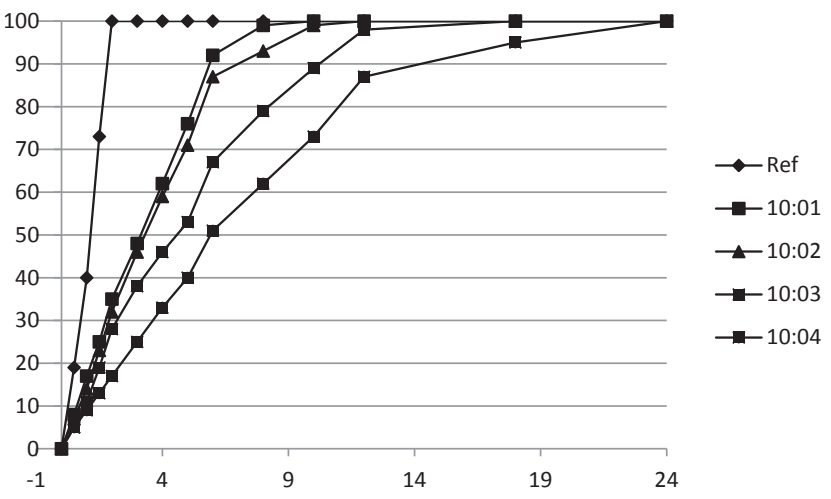

Figure 2: In vitro Release of Mefenamic acid in Phosphate Buffer 7.2.

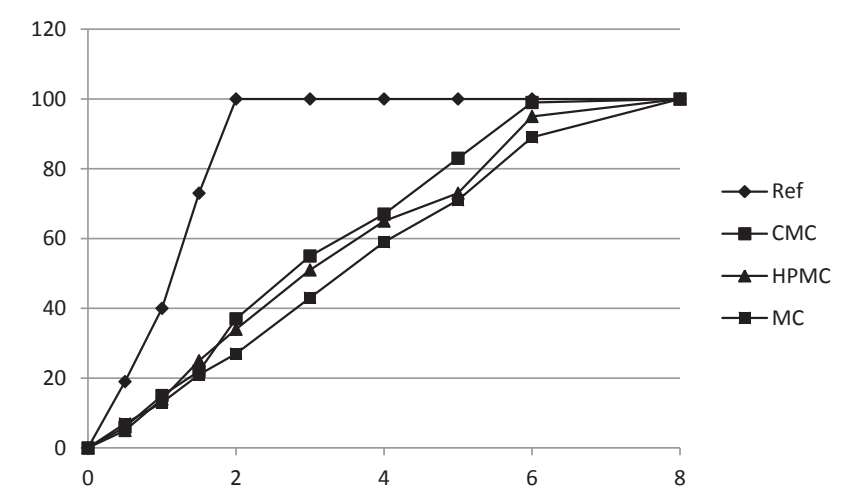

Figure 3: In vitro Release of Mefenamic acid containing co-excipients D: P ratio $10: 4$ 
Citation: Usman M, Ali I, Bibi H, Iqbal J, Iqbal K (2012) Preparation and Evaluation of Controlled Release Tablets Containing Mefenamic Acid. Clin Exp Pharmacol 2:107. doi:10.4172/2161-1459.1000107

were found to have a dramatic enhancement effect on drug release rates from controlled release tablets. It is suggested that CMC, HPMC are water absorbable polymers and when exposed to water they are hydrated and thus cause the rupture of tablet by increasing the osmotic pressure of the internal tablet, similar results were found in the studies of several other investigators [7,4]. Several kinetic models were employed to the dissolution data of Mefenamic acid controlled release tablets in phosphate buffer and the mechanism of drug release was investigated during which it was found that the drug exhibited linear profiles and anomalous nearly zero order non-Fickian transport mechanism. While employing these kinetic models similar values were found by [7]. Dissolution equivalency $\mathrm{f}_{2}$ was applied to the dissolution profiles of formulations from the test and a reference formulation to compare the release profiles with respect to drug release rate per unit time and were found that the values of $\mathrm{f}_{2}$ were smaller than 50 (range 50-100) so it concludes that a large difference was present between the different release profiles of test formulations as compared to reference standard formulation [7].

\section{Conclusion}

From the above study Ethocel was found to be an effective rate controlling polymer. In this study it was also found that the concentration of polymer have also a tremendous effect on drug release rates, by increasing the amount of polymer drug release rate can be reduced to a high value. Several co-excipients added to selected optimized formulation showed enhancement effect on drug release rates and by the addition of these co-excipients the formulations exhibited more substantial enhanced drug release rates.

\section{References}

1. Cleary GW (1991) Transdermal Drug Delivery. Cosm Toilet 106: 97-107.

2. FDA (1997) US Department of Health and Human Services, Food And Drug Administration, Guidance for Industry: Dissolution Testing of Immediate Release Solid Dosage Forms.

3. Gohel MC, Panchal MK (2002) Novel use of Similarity Factor $\mathrm{f} 2$ and Sd for the development of diltiazem $\mathrm{HCl}$ modified-release tablets using a 3(2) factorial Design. Drug Dev Ind Pharm 28: 77-87.

4. Khan GM, Zhu JB (2001) Evaluation of Ethocel Premium Ethylcellulose Derivatives with Different Molecular Weights as Controlled-release Matrix Forming Functional Polymers For Ibuprofen. The sciences 1: 361-367.

5. Lakshmana PS, Shirwaikar AA, Shirwaikar A, Ravikumar G, Kumar A, et al. (2009) Formulation and evaluation of oral sustained release of Diltiazem Hydrochloride using rosin as matrix forming material. Ars Pharm 50: 32-42.

6. http://en.wikipedia.org/wiki/Mefenamic_acid.

7. Shah SU, Shah KU, Rehman A and Khan GM (2011) Investigating the in vitro drug release kinetics from controlled release Diclofenac Potassium-Ethoce matrix tablets and the influence of Co-excipients on drug release patterns. Pak J Pharm Sci 24: 183-192.

8. Maswadeh HA, Al-Hanbali OA, Kanaan RA, Shakya AK, Maraqa A (2010) Testing lyoequivalency for three commercially sustained release Tablets containing diltiazem hydrochloride. Acta pol pharm 67: 93-97. 